\title{
SIMPLY OPTIMAL - BEYOND EOQ FOR A POPULAR CLASS OF INVENTORY PROBLEMS
}

\author{
Dr. W. van Wijck Pr.Eng. Ph.D. Eng. \\ Department of Industrial Engineering \\ University of Stellenbosch
}

\section{ABSTRACT:}

True optimal solutions to real life problems are normally only achievable at the expense of great complexity. Every now and then however, one is almost stunned by the simplicity of a good solution to a practical problem. This paper discusses a relatively simple method for determining the joint optimum order quantity and reorder point for the case where service level is specified as a desired fraction of demand to be satisfied directly from stock. Separate solutions were derived for complete backorders and lost sales, and the method is equally applicable to fixed order quantity and periodic review inventory problems. Demand during the lead time is assumed to be normally distributed. The intent of the paper is to focus on the findings and the application of the method, rather than the mathematical derivation of the formulae itself.

\section{OPSOMMING:}

Ware optimale oplossings vir werklike praktiese probleme is gewoonlik net bereikbaar ten koste van groot kompleksiteit. Elke nou en dan staan 'n mens egter bykans verstom omtrent die eenvoud van ' $n$ voortreflike oplossing vir ' $n$ bepaalde probleem. Hierdie artikel bespreek ' $n$ relatief eenvoudige metode om die gesamentlike optimale bestel-grootte en veiligheidsvoorraad te bepaal, vir die geval waar dienspeil uitgedruk word as die proporsie van voorraad-items wat op eerste aanvraag direk uit voorraad op hande voorsien word. Aparte oplossings is gevind vir die gevalle van volledige agterstallige bestellings en volledige verlore verkope, en die metode is ewe toepaslik vir vaste bestel-hoeveelheid- en periodieke hersiening-voorraad-stelsels. Die normaal-verdeling is as die statistiese verdeling van aanvraag gedurende die leityd aanvaar. Die artikel fokus op toepassing en bevindings eerder as op die wiskundige afleiding van die formules.

\section{INTRODUCTION}

Inventory literature distinguishes between two metrics of service, namely:

- a service level based on service per order cycle (service per cycle)

- a service level based on the total number of units demanded (service per unit)

The first metric above depends on the probability of a stockout during a replenishment cycle and is the most widely discussed measure in the literature. The second metric is defined as follows:

$$
\mathrm{P}=\frac{\text { Number of units supplied directly from stock }}{\text { Total number of units demanded }}
$$

This paper is concerned with inventory systems in which the second service metric applies. In such systems, the safety stock and the order quantity (or the maximum inventory level, in the case of periodic review systems) jointly determine the service level (second measure above). If the order 
size is increased, the service level will automatically increase if the safety stock is held constant. A desired service level can thus be obtained using various combinations of order quantity and safety stock.

This specific class of inventory problems is extensively documented and discussed in the literature, although it seems to remain overshadowed by the service per cycle class of problems, largely due to the former's greater complexity. In many (if not most) cases however, service per unit is what really counts, and therefore a decision rule is needed that can compete with its counterpart in the service per cycle category. Up until now, the literature (see e.g. Chase [1] and Tersine [2]) has suggested the use of the standard EOQ as the order quantity, with safety stock (and reorder point) adjusted afterwards to assure the desired service level. However, this process of establishing the order quantity and safety stock separately and independently from each other, leads to a suboptimal solution. Narasimhan [3] acknowledged this fact and discuss an iterative method for obtaining a joint optimum pair of values for order quantity and safety stock.

The method discussed in this paper allows for the direct calculation of the joint optimum of safety stock and order quantity for problems in which the service per unit metric is used. An example is used to illustrate the simplicity and optimality of the mathematical solution.

\section{LIST OF SYMBOLS}

$\mathrm{A}(\mathrm{z}, \mathrm{P})$ : A derived value, necessary for calculating the optimal parameters of the Backorder inventory problem and tabulated in table 2 .

$\mathrm{B}(\mathrm{z}, \mathrm{P})$ : A derived value, necessary for converting the EOQ to a truly optimum order quantity $\left(\mathrm{Q}^{\circ}\right)$ for the Backorder inventory problem and tabulated in table 3 .

$\mathrm{C}(\mathrm{z}, \mathrm{P})$ : A derived value, necessary for calculating the optimal parameters of the Lost Sales inventory problem and tabulated in table 4.

$\mathrm{D}(\mathrm{z}, \mathrm{P})$ : A derived value, necessary for converting the EOQ to a truly optimum order quantity $\left(\mathrm{Q}^{\circ}\right)$ for the Lost Sales inventory problem and tabulated in table 5.

D : Annual demand for inventory item

EOQ : Economic ordering quantity (not optimal for this particular inventory case)

$\mathrm{E}(\mathrm{z})$ : Expected shortage per replenishment cycle when demand during lead time has a standard normal distribution

$\mathrm{f}(\mathrm{z}) \quad$ : Normal probability density function

$\mathrm{F}(\mathrm{z}) \quad$ : (Cumulative) Normal distribution function, i.e. $\mathrm{P}(\mathrm{Z}<\mathrm{z})$

$\mathrm{H} \quad$ : Annual inventory holding cost

$\mathrm{P} \quad$ : Service level based on the service per unit metric

Q : : General symbol for order quantity

$Q^{\circ} \quad$ : Optimal order quantity

$\mathrm{S} \quad$ : Order cost

TRC : Annual total relevant inventory cost

$z \quad$ : A particular outcome of $Z$

$\sigma_{\mathrm{dLT}} \quad$ : Standard deviation of demand during the lead time 


\section{THEORETICAL OVERVIEW}

The most widely used procedure to calculate the safety stock of inventory problems with a per unit measure of service, was proposed by Brown [4] in 1967. Brown assumed that demand during the lead time is normally distributed and proceeded to quantify and tabulate the relationship between safety stock and expected shortage per replenishment cycle. From this table the necessary safety stock can easily be calculated if the order quantity (in Brown's case the EOQ), the desired service level $(\mathrm{P})$ and the degree of uncertainty of demand during the lead time $\left(\sigma_{\mathrm{dLT}}\right)$ is known. The foregoing procedure determines the right amount of safety stock to ensure the desired service level, given an order quantity that equals the EOQ. A higher (or lower) order quantity than the EOQ, combined with a lower (or higher) level of safety stock will however also ensure the same level of service. The problem therefore is to determine the pair that will minimise the total annual relevant inventory cost.

The procedure leading to the joint optimum solution of the two variables of the particular class of inventory problems presented in this paper, is basically the same as the one proposed by Brown. The main difference is that a new set of four tables was generated - two for complete backorders, and another two for complete lost sales. Where Brown's solution involved one table-lookup, the new procedure involves two table-lookups. Because the effect of complete lost sales on service is different from that of complete backorders, the two cases were analysed separately. Similar (but different) results were obtained. In both cases, the ratio of the standard deviation of demand during the lead time $\left(\sigma_{\mathrm{dLT}}\right)$ to the EOQ, proved to be an important input to the optimal solution. The most important relationships obtained from the analysis are summarised in table 1 below.

Table 1. Important mathematical relationships for obtaining the joint optima of the two variables for the particular class of inventory problems

\begin{tabular}{|c|c|c|c|c|}
\hline & Complete Back & ers & \multicolumn{2}{|c|}{ Complete Lost Sales } \\
\hline \multirow{3}{*}{ 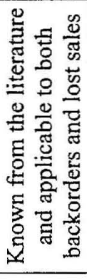 } & \multicolumn{4}{|c|}{$E(z)=f(z)-z-z \cdot F(z)$} \\
\hline & & EOQ & $\sqrt{\frac{2 \mathrm{DS}}{\mathrm{H}}}$ & \\
\hline & & $\sigma_{\mathrm{dLT}}$ & $\sqrt{\overline{\mathrm{L}} \sigma_{\mathrm{d}}^{2}+\overline{\mathrm{d}}^{2} \sigma_{\mathrm{L}}^{2}}$ & \\
\hline 总范口 & $A(z, P)=\frac{1-P}{E(z) \cdot B(z, P)}$ & See table 2 & $C(z, P)=\left(\frac{1}{P}-1\right) \frac{1}{E(z) \cdot D(z, P)}$ & See table 4 \\
\hline 邑 & $B(z, P)=\sqrt{1-2 \frac{1-P}{1-F(z)}}$ & See table 3 & $\mathrm{D}(\mathrm{z}, \mathrm{P})=\frac{1}{\mathrm{P}} \sqrt{\mathrm{P}-2\left(\frac{1-\mathrm{P}}{1-\mathrm{F}(\mathrm{z})}\right)}$ & See table 5 \\
\hline & $\mathrm{Q}^{0}=\frac{\mathrm{EOQ}}{\mathrm{B}(\mathrm{z}, \mathrm{P})}$ & & $\mathrm{Q}^{\mathrm{o}}=\frac{\mathrm{EOQ}}{\mathrm{D}(\mathrm{z}, \mathrm{P})}$ & \\
\hline
\end{tabular}

Referring to table 1 , it can be seen that the expressions $A(z, P), B(z, P), C(z, P)$ and $D(z, P)$ are all functions of only two variables, namely $z$ and $P$. These functions have been tabulated for various values of $z$ and $P$. For the complete backorders problem, the table of $A(z, P)$ (table 2) is used to obtain the optimal value of $z$, from which the safety stock can be calculated. Once $z$ is known, the value of $\mathrm{B}(\mathrm{z}, \mathrm{P})$ can be determined from table 3 , to convert the EOQ to a truly optimal order 
quantity. The procedure for the complete lost sales case is identical, except that $\mathrm{C}(\mathrm{z}, \mathrm{P})$ (table 4 ) is used instead of $\mathrm{A}(\mathrm{z}, \mathrm{P})$ (table 2) and $\mathrm{D}(\mathrm{z}, \mathrm{P})$ (table 5) is used instead of $\mathrm{B}(\mathrm{z}, \mathrm{P})$ (table 3 ).

\section{APPLYING THE PROCEDURE}

This section provides a step-by-step procedure for determining the optimum order quantity and safety stock for a fixed order quantity problem using the formulae and tables that were introduced in the previous section. The same basic approach can be applied to Periodic review systems.

Step 1: Calculate the EOQ using the standard formula: $E O Q=\sqrt{\frac{2 \mathrm{DS}}{\mathrm{H}}}$

Step 2: Determine the standard deviation of demand during the lead time " $\sigma_{\mathrm{dLT}}$ ", using appropriate equations from the literature depending on whether only demand, only lead time or both are variable.

Step 3: Calculate the ratio: $\frac{\sigma_{\mathrm{dLT}}}{\mathrm{EOQ}}$

Step 4: Backorders: Find a value for $A(z, P)$ in the column corresponding to the required service level "P" from table 2 that matches the ratio calculated in step 3, and then read the corresponding value of " $\mathrm{z}$ ".

Lost sales: Find a value for $\mathrm{C}(\mathrm{z}, \mathrm{P})$ in the column corresponding to the required service level "P" from table 4 that matches the ratio calculated in step 3 , and then read the corresponding value of " $\mathrm{z}$ ".

Note, to be able to match the ratio calculated in step 3, linear interpolation between the values of the respective tables may be necessary.

Step 5: Calculate the safety stock using the standard formula: safety stock $=\mathrm{z} \cdot \sigma_{\mathrm{dLT}}$

Step 6: Calculate the reorder point by adding the average demand during the lead time to the safety stock calculated in step 5 above.

Step 7: Backorders: With the value of "z" obtained from table 2 in step 4, use table 3 to read off the corresponding value of $\mathrm{B}(\mathrm{z}, \mathrm{P})$ in the column corresponding to the required service level "P".

Lost sales: With the value of " $\mathrm{z}$ " obtained from table 4 in step 4, use table 5 to read off the corresponding value of $\mathrm{D}(\mathrm{z}, \mathrm{P})$ in the column corresponding to the required service level "P".

Again, linear interpolation may be necessary.

Step 8: Backorders: Finally calculate the optimal order using $Q^{\circ}=\frac{E O Q}{B(z, P)}$

Lost sales: Finally calculate the optimal order using $Q^{\circ}=\frac{E O Q}{D(z, P)}$ 


\section{A NUMERICAL EXAMPLE}

Assume that the following information about an inventory item is known:

$\mathrm{D}=500$ p.a.

$\mathrm{H}=\mathrm{R} 16$ per unit p.a.

$\mathrm{S}=\mathrm{R} 40$

$\mathrm{P}=92 \%$ (i.e. $92 \%$ of the total demand must be satisfied from stock on hand)

Average lead time $=4$ weeks (assume 52 weeks per year)

$\sigma_{\mathrm{dLT}}=20$

The example will first be solved for the case of complete backorders and then for the case of complete lost sales.

\section{Backorders:}

Step 1: Calculate the EOQ: $\mathrm{EOQ}=\sqrt{\frac{2(500) 40}{16}}=50$

Step 2: Not necessary, $\sigma_{\mathrm{dLT}}$ is given.

Step 3: Calculate the ratio: $\frac{\sigma_{\mathrm{dLT}}}{\mathrm{EOQ}}=\frac{20}{50}=0,4$

Step 4: Use table 2 to find the value of " $\mathrm{z}$ " that corresponds with $\mathrm{A}(\mathrm{z}, 92 \%)=0,4$. Using interpolation, $z$ 's value is obtained as 0,3082 .

Step 5: Using the "z" obtained in step 4 above, the safety stock $=(0,3082)(20)=6,164$.

Step 6: Next the reorder point can be calculated: $R O P=\left(\frac{500}{52}\right)(4)+6,164=44,63 \cong 45$

Step 7: With $\mathrm{z}=0,3082$ the corresponding value of $\mathrm{B}(\mathrm{z}, 92 \%)$ is obtained from table 3 (again by linear interpolation) as $\mathrm{B}(\mathrm{z}, 92 \%)=0,76$

Step 8: Finally the optimal order quantity is found as $\mathrm{Q}^{\circ}=\frac{50}{0,76}=65,79 \cong 66$

To illustrate the optimality of the above solution, the TRC has been calculated for various combinations of order quantity and safety stock that will ensure the desired service level of $92 \%$. For this purpose, order quantities within the range $[40,92]$ were chosen arbitrarily and the corresponding values of $\mathrm{z}$ that will ensure the desired service level of $92 \%$ were calculated. The TRC was then calculated for each of these combinations and a graph of TRC versus $\mathrm{Q}$ was drawn. The reader is referred to this graph which appears in Figure 1. It is clear from the graph that the order quantity of 66 and the safety stock of 6,164 are optimal for this specific example. It should also be noted that the standard EOQ is not optimal and that a saving on annual inventory costs of about R28 (2,96\%) was possible using the proposed order quantity instead of the EOQ.

\section{Lost sales:}

Step 1: Calculate the EOQ: (same as for backorders) $\mathrm{EOQ}=50$.

Step 2: Not necessary, $\sigma_{\mathrm{dLT}}$ is given. 
Step 3: Calculate the ratio: (same as for backorders) $\frac{\sigma_{\mathrm{dLT}}}{\mathrm{EOQ}}=0,4$

Step 4: Use table 4 to find the value of " $z$ " that corresponds with $C(z, 92 \%)=0,4$. Using interpolation, $z$ 's value is obtained as 0,2657 .

Step 5: Using the " $z$ " obtained in step 4 above, the safety stock $=(0,2657)(20)=5,314$.

Step 6: Next the reorder point can be calculated: $\operatorname{ROP}=\left(\frac{500}{52}\right)(4)+5,314=43,78 \cong 44$

Step 7: With $z=0,2657$ the corresponding value of $\mathrm{D}(\mathrm{z}, 92 \%)$ is obtained from table 5 (again by linear interpolation) as $\mathrm{D}(\mathrm{z}, 92 \%)=0,7795$

Step 8: Finally the optimal order quantity is found as $\mathrm{Q}^{\circ}=\frac{50}{0,7795}=64,14 \cong 64$

As before, to illustrate the optimality of the above solution, the TRC has been calculated for various combinations of order quantity and safety stock that will ensure the desired service level of $92 \%$. In this case, order quantities within the range $[38,90]$ were chosen arbitrarily and the corresponding values of $\mathrm{z}$ that will ensure the desired service level of $92 \%$ were calculated. The TRC was then calculated for each of these combinations and a graph of TRC versus $Q$ was drawn. The reader is referred to this graph which appears in figure 2. It is clear from the graph that the order quantity of 64 and the safety stock of 5,314 are optimal for this specific example. Again it should also be noted that the standard EOQ is not optimal and that a saving on annual inventory costs of about R22 $(2,46 \%)$ was possible using the proposed order quantity instead of the EOQ.

\section{CONCLUDING REMARKS}

Studying the values of $B(z, P)$ in table 3 and $D(z, P)$ in table 5 , it will be noticed that all the values within these two tables are less than one. This fact was also verified mathematically, by studying the mathematical upper bounds of $B(z, P)$ and $D(z, P)$. In essence, what this means is that the optimal order quantity $\left(\mathrm{Q}^{\circ}\right)$ will always be larger than the EOQ. This is true for complete backorders as well as complete lost sales. Furthermore, the larger order quantities of the joint optimisation method, also result in correspondingly lower safety stocks for the same service levels. This means that the ratio of order quantity (cycle stock) to safety stock will be different for the traditional and proposed methods. Expressions for the ratio of order quantity (cycle stock) to safety stock have been derived for both backorders and lost sales and for both methods. A graph showing ratios of order quantity to cycle stock for the new method plotted against corresponding ratios of the old method (corresponding in the sense that the same service $\mathrm{P}$ and the same ratio of $\sigma_{\mathrm{dLT}}$ to EOQ were used for a particular point) for the case of backorders, appear in figure 3 . A similar graph for lost sales appears in figure 4 . Both graphs were drawn for arbitrarily chosen service levels $\mathrm{P}=\{0,93 ; 0,95 ; 0,97 ; 0,99\}$. The graphs indicate the following:

- It confirms the previous conclusion that larger order quantities and less safety stock ate employed by the new method to achieve the desired service level. The new method therefore reduces the safety stock and relies on larger order sizes to ensure the specified service level.

- The higher the service level, the less difference there is between the old and the proposed new methods. When $P=0,99$, the relationship between the two ratios is very close to the $45^{\circ}$ line $Y$ $=\mathrm{X}$. As the service level is decreased, the difference between the two methods rapidly becomes 
significant. Even at a still relatively high service level of 0,95 , substantially higher order quantities and less safety stock are suggested by the new method.

- The difference between the old and the new method is greater for large EOQ's and small safety stocks.

- There is a very close resemblance between figures 3 and 4 , meaning that everything that was said above, apply equally well to backorders and lost sales. The difference between the old and proposed methods, however is slightly less for lost sales than for backorders (figure 3 has steeper gradients than figure 4), although the magnitude of this difference is so small, that the distinction is purely academical.

To conclude, the proposed procedure for calculating the optimal order quantity and safety stock presented in this paper is no more complex than the current method of first calculating the EOQ and then determining the safety stock to ensure a specified service level. A substantial saving in annual inventory cost is possible ( $2,5 \%$ and more) when the joint optima of order quantity and safety stock are used instead of the popularly quoted individually optimised values.

\section{REFERENCES}

[1] Chase, R. B. and Aquilano, N. J. (1995), Production and Operations Management Manufacturing and Services, Richard D. Irwin, Chicago, pp. 555-562.

[2] Tersine, R. J. (1994), Principles of Inventory and Materials Management, Prentice-Hall, Englewood Cliffs, New Jersey, pp. 238-240.

[3] Narasimhan, S. L., McLeavey, D. W. and Billington, P. J. (1995), Production Planning and Inventory Control, Prentice-Hall, Englewood Cliffs, New Jersey, pp. 154-156.

[4] Brown, R. G. (1967), Decision Rules for Inventory Management, Rinehart \& Winston, New York. 


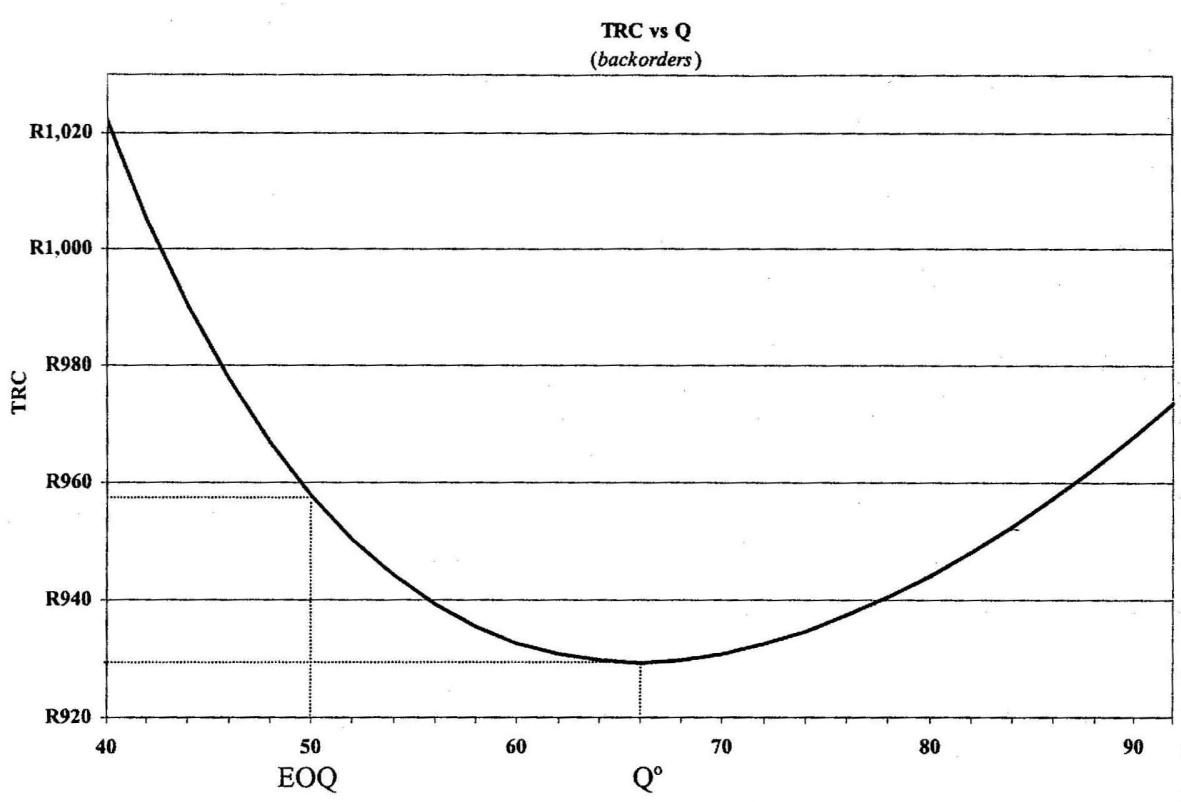

Figure 1. TRC : EOQ versus $\mathrm{Q}^{\circ}$ (backorders)

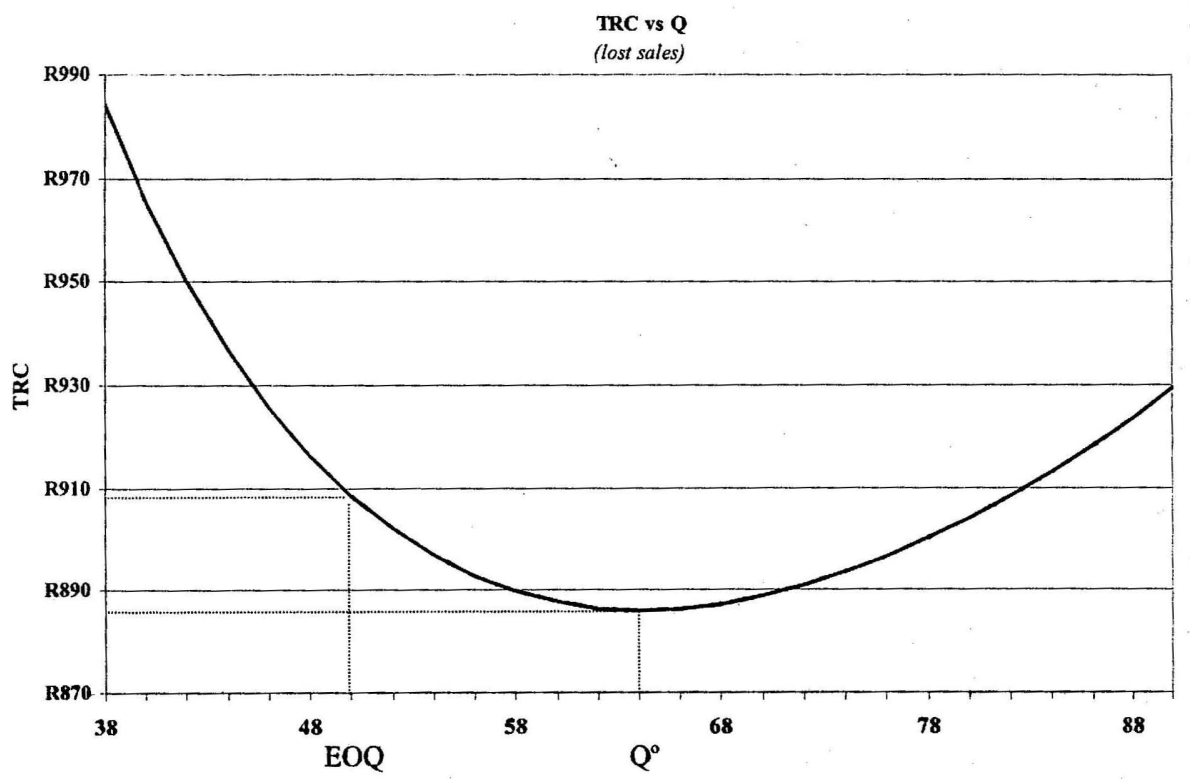

Figure 2. TRC: EOQ versus $Q^{\circ}$ (lost sales) 


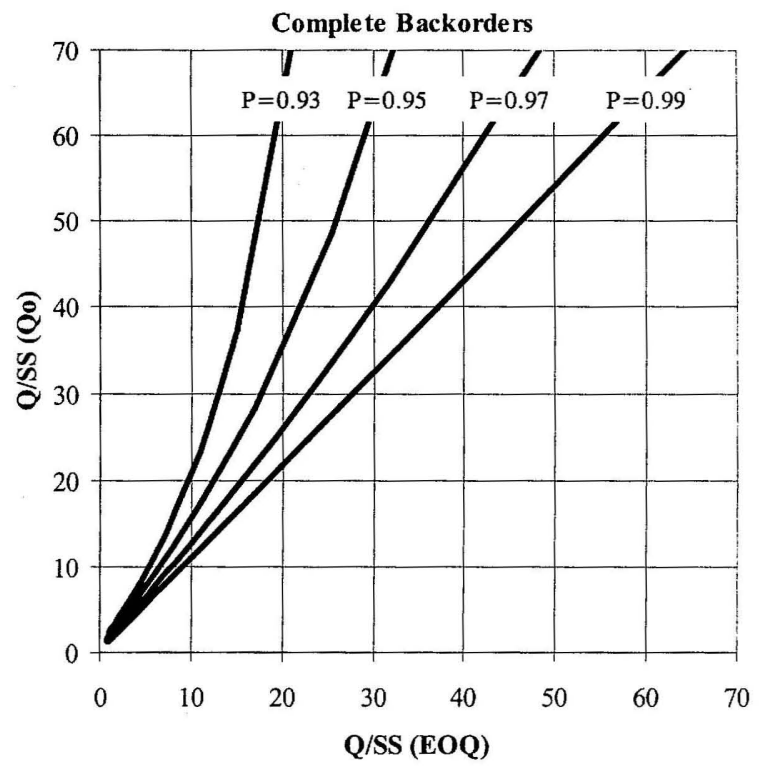

Figure 3. Ratio of order quantity to safety stock - new method plotted against old method (Backorders)

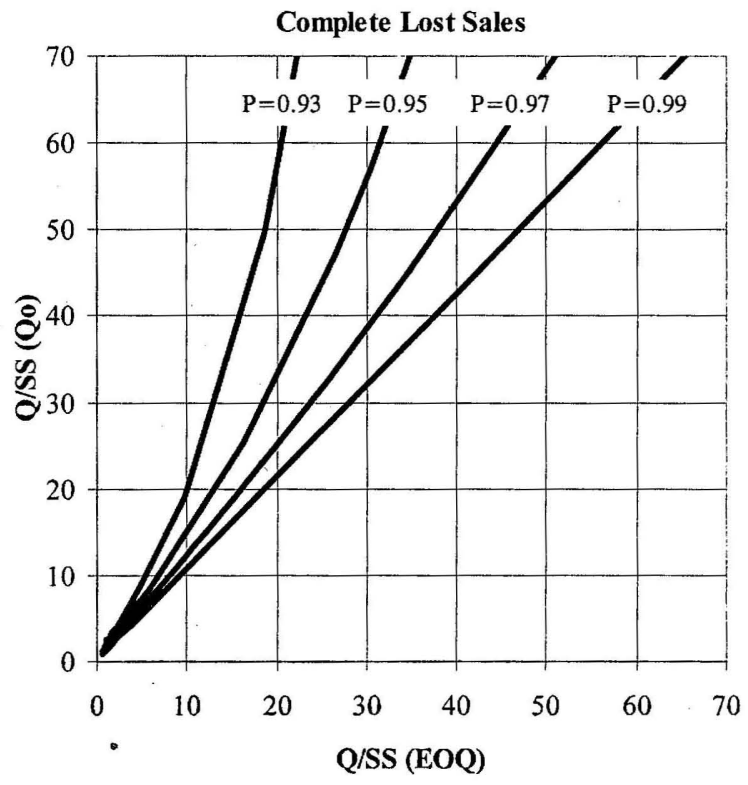

Figure 4. Ratio of order quantity to safety stock - new method plotted against old method (Lost sales) 
Table 2. Tabulated values of $A(z, P)$ for various values of $z$ and $P$

\begin{tabular}{|c|c|c|c|c|c|c|c|c|c|c|c|c|}
\hline$z \backslash P$ & 0.80 & 0.85 & 0.90 & 0.91 & 0.92 & 0.93 & 0.94 & 0.95 & 0.96 & 0.97 & 0.98 & 0.99 \\
\hline-3.0 & 0.08609 & 0.05977 & 0.03727 & 0.03313 & 0.02910 & 0.02516 & 0.02132 & 0.01757 & 0.01390 & 0.01031 & 0.00680 & 0.00337 \\
\hline-2.9 & 0.08907 & 0.06184 & 0.03855 & 0.03427 & 0.03010 & 0.02603 & 0.02205 & 0.01817 & 0.01438 & 0.01067 & 0.00704 & 0.00348 \\
\hline-2.8 & 0.09227 & 0.06405 & 0.03993 & 0.03550 & 0.03117 & 0.02696 & 0.02284 & 0.01882 & 0.01489 & 0.01105 & 0.00729 & 0.00361 \\
\hline-2.7 & 0.09570 & 0.06643 & 0.04141 & 0.03681 & 0.03233 & 0.02795 & 0.02369 & 0.01952 & 0.01544 & 0.01146 & 0.00756 & 0.00374 \\
\hline-2.6 & 0.09941 & 0.06899 & 0.04300 & 0.03822 & 0.03357 & 0.02903 & 0.02459 & 0.02026 & 0.01603 & 0.01190 & 0.00785 & 0.00388 \\
\hline-2.5 & 0.10341 & 0.07175 & 0.04472 & 0.03975 & 0.03491 & 0.03018 & 0.02557 & 0.02107 & 0.01667 & 0.01237 & 0.00816 & 0.00404 \\
\hline-2.4 & 0.10776 & 0.07475 & 0.04658 & 0.04140 & 0.03636 & 0.03144 & 0.02663 & 0.02195 & 0.01736 & 0.01288 & 0.00850 & 0.00420 \\
\hline-2.3 & 0.11249 & 0.07801 & 0.04860 & 0.04320 & 0.03793 & 0.03280 & 0.02779 & 0.02289 & 0.01811 & 0.01344 & 0.00886 & 0.00439 \\
\hline-2.2 & 0.11766 & 0.08156 & 0.05080 & 0.04515 & 0.03964 & 0.03427 & 0.02904 & 0.02392 & 0.01893 & 0.01404 & 0.00926 & 0.00458 \\
\hline-2.1 & 0.12332 & 0.08545 & 0.05320 & 0.04728 & 0.04151 & 0.03589 & 0.03040 & 0.02505 & 0.01981 & 0.01470 & 0.00969 & 0.00480 \\
\hline-2.0 & 0.12956 & 0.08971 & 0.05583 & 0.04961 & 0.04356 & 0.03765 & 0.03190 & 0.02627 & 0.02078 & 0.01542 & 0.01017 & 0.00503 \\
\hline-1.9 & 0.13646 & 0.09441 & 0.05872 & 0.05218 & 0.04580 & 0.03959 & 0.03354 & 0.02762 & 0.02185 & 0.01621 & 0.01069 & 0.00529 \\
\hline-1.8 & 0.14412 & 0.09962 & 0.06191 & 0.05501 & 0.04828 & 0.04173 & 0.03534 & 0.02911 & 0.02302 & 0.01708 & 0.01126 & 0.00557 \\
\hline-1.7 & 0.15266 & 0.10540 & 0.06545 & 0.05814 & 0.05103 & 0.04410 & 0.03734 & 0.03075 & 0.02432 & 0.01803 & 0.01189 & 0.00588 \\
\hline-1.6 & 0.16223 & 0.11185 & 0.06938 & 0.06162 & 0.05407 & 0.04672 & 0.03956 & 0.03257 & 0.02576 & 0.01910 & 0.01259 & 0.00623 \\
\hline-1.5 & 0.17301 & 0.11907 & 0.07377 & 0.06551 & 0.05747 & 0.04965 & 0.04203 & 0.03460 & 0.02735 & 0.02028 & 0.01337 & 0.00661 \\
\hline-1.4 & 0.18523 & 0.12721 & 0.07869 & 0.06986 & 0.06127 & 0.05292 & 0.04479 & 0.03687 & 0.02914 & 0.02160 & 0.01423 & 0.00704 \\
\hline-1.3 & 0.19914 & 0.13641 & 0.08423 & 0.07475 & 0.06554 & 0.05660 & 0.04789 & 0.03941 & 0.03114 & 0.02308 & 0.01520 & 0.00752 \\
\hline-1.2 & 0.21509 & 0.14688 & 0.09049 & 0.08028 & 0.07037 & 0.06074 & 0.05138 & 0.04227 & 0.03339 & 0.02474 & 0.01629 & 0.00805 \\
\hline-1.1 & 0.23350 & 0.15885 & 0.09761 & 0.08655 & 0.07583 & 0.06543 & 0.05533 & 0.04550 & 0.03593 & 0.02661 & 0.01752 & 0.00866 \\
\hline-1.0 & 0.25490 & 0.17262 & 0.10573 & 0.09370 & 0.08206 & 0.07077 & 0.05982 & 0.04917 & 0.03882 & 0.02874 & 0.01892 & 0.00934 \\
\hline-0.9 & 0.28000 & 0.18855 & 0.11505 & 0.10190 & 0.08919 & 0.07688 & 0.06494 & 0.05335 & 0.04210 & 0.03115 & 0.02050 & 0.01012 \\
\hline-0.8 & 0.30971 & 0.20713 & 0.12580 & 0.11134 & 0.09738 & 0.08388 & 0.07082 & 0.05815 & 0.04586 & 0.03392 & 0.02231 & 0.01101 \\
\hline-0.7 & 0.34526 & 0.22894 & 0.13828 & 0.12228 & 0.10686 & 0.09198 & 0.07759 & 0.06367 & 0.05018 & 0.03709 & 0.02438 & 0.01202 \\
\hline-0.6 & 0.38837 & 0.25478 & 0.15285 & 0.13502 & 0.11788 & 0.10137 & 0.08544 & 0.07005 & 0.05517 & 0.04075 & 0.02677 & 0.01319 \\
\hline-0.5 & 0.44146 & 0.28569 & 0.16998 & 0.14997 & 0.13077 & 0.11233 & 0.09458 & 0.07748 & 0.06096 & 0.04499 & 0.02953 & 0.01454 \\
\hline-0.4 & 0.50818 & 0.32310 & 0.19029 & 0.16762 & 0.14596 & 0.12521 & 0.10530 & 0.08615 & 0.06771 & 0.04993 & 0.03274 & 0.01611 \\
\hline-0.3 & 0.59423 & 0.36898 & 0.21455 & 0.18863 & 0.16397 & 0.14044 & 0.11793 & 0.09636 & 0.07564 & 0.05571 & 0.03649 & 0.01794 \\
\hline-0.2 & 0.70926 & 0.42619 & 0.24381 & 0.21386 & 0.18551 & 0.15858 & 0.13294 & 0.10844 & 0.08500 & 0.06251 & 0.04089 & 0.02008 \\
\hline-0.1 & 0.87146 & 0.49906 & 0.27950 & 0.24446 & 0.21150 & 0.18037 & 0.15088 & 0.12284 & 0.09611 & 0.07057 & 0.04609 & 0.02260 \\
\hline 0.0 & 1.12100 & 0.59450 & 0.32360 & 0.28200 & 0.24318 & 0.20679 & 0.17252 & 0.14012 & 0.10940 & 0.08016 & 0.05227 & 0.02558 \\
\hline 0.1 & 1.57603 & 0.72449 & 0.37897 & 0.32867 & 0.28225 & 0.23913 & 0.19885 & 0.16105 & 0.12540 & 0.09167 & 0.05964 & 0.02914 \\
\hline 0.2 & 2.93522 & 0.91239 & 0.44986 & 0.38769 & 0.33113 & 0.27923 & 0.23125 & 0.18660 & 0.14483 & 0.10557 & 0.06851 & 0.03339 \\
\hline 0.3 & - & 1.21313 & 0.54302 & 0.46391 & 0.39336 & 0.32966 & 0.27157 & 0.21814 & 0.16864 & 0.12249 & 0.07924 & 0.03851 \\
\hline 0.4 & - & 1.80975 & 0.66994 & 0.56513 & 0.47434 & 0.39424 & 0.32252 & 0.25754 & 0.19809 & 0.14325 & 0.09231 & 0.04471 \\
\hline 0.5 & - & 4.55890 & 0.85240 & 0.70496 & 0.58292 & 0.47883 & 0.38805 & 0.30748 & 0.23497 & 0.16899 & 0.10838 & 0.05228 \\
\hline 0.6 & $\ldots$ & - & 1.13939 & 0.91018 & 0.73483 & 0.59315 & 0.47431 & 0.37189 & 0.28178 & 0.201 .23 & 0.12830 & 0.06157 \\
\hline 0.7 & - & - & 1.68062 & 1.24474 & 0.96202 & 0.75471 & 0.59148 & 0.45686 & 0.34218 & 0.24212 & 0.15321 & 0.07307 \\
\hline 0.8 & - & - & 3.51667 & 1.93081 & 1.34519 & 0.99990 & 0.75803 & 0.57244 & 0.42179 & 0.29478 & 0.18473 & 0.08742 \\
\hline 0.9 & - & - & - & 6.03373 & 2.20319 & 1.42458 & 1.01267 & 0.73669 & 0.52970 & 0.36385 & 0.22510 & 0.10547 \\
\hline 1.0 & - & - & - & - & & 2.45019 & 1.45898 & 0.98700 & 0.68186 & 0.45663 & 0.27758 & 0.12839 \\
\hline 1.1 & - & - & - & - & - & & 2.57311 & 1.42112 & 0.91002 & 0.58541 & 0.34709 & 0.15783 \\
\hline 1.2 & - & - & - & - & - & - & & 2.46273 & 1.29150 & 0.77297 & 0.44136 & 0.19610 \\
\hline 1.3 & - & - & - & - & - & - & - & & 2.10892 & 1.06870 & 0.57348 & 0.24659 \\
\hline 1.4 & - & - & - & - & - & - & - & - & 11.2693 & 1.61378 & 0.76777 & 0.31442 \\
\hline 1.5 & - & - & - & - & - & - & - & - & - & 3.20686 & 1.07733 & 0.40765 \\
\hline 1.6 & - & - & - & - & - & - & - & - & - & & 1.65586 & 0.53992 \\
\hline 1.7 & - & - & - & - & - & - & - & - & - & - & 3.41685 & 0.73650 \\
\hline 1.8 & - & - & - & - & - & - & - & - & - & - & & 1.05201 \\
\hline 1.9 & - & - & - & - & - & . & - & - & - & - & - & 1.64194 \\
\hline 2.0 & - & - & - & - & - & & - & - & 6 & - & - & 3.38742 \\
\hline 2.1 & . & - & - & - & - & 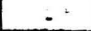 & - & - & - & - & - & - \\
\hline
\end{tabular}

Maximum values of $\mathrm{z}$ for which $\mathrm{A}(\mathrm{z}, \mathrm{P})=\infty$

\begin{tabular}{|l|l|l|l|l|l|l|l|l|l|l|l|}
\hline 0.25335 & 0.52440 & 0.84162 & 0.91537 & 0.99446 & 1.08032 & 1.17499 & 1.28155 & 1.40507 & 1.55477 & 1.75069 & 2.05375 \\
\hline
\end{tabular} 


\begin{tabular}{|c|c|c|c|c|c|c|c|c|c|c|c|c|}
\hline$z \backslash \mathbf{P}$ & 0.80 & 0.85 & 0.90 & 0.91 & 0.92 & 0.93 & 0.94 & 0.95 & 0.96 & 0.97 & 0.98 & 0.99 \\
\hline 3.0 & 0.77425 & 0.83642 & 89428 & 0.90540 & 0.91640 & 0.92726 & 0.93800 & 0.94861 & 0.95911 & 0.96949 & 0.97977 & 0.98994 \\
\hline-2.9 & & 3632 & & 535 & & 2722 & & & & & & \\
\hline-2.8 & 77393 & 83620 & 89414 & 90528 & 0.91629 & 0.92717 & 93792 & 94855 & 95906 & 96946 & 97974 & 98992 \\
\hline-2.7 & 77370 & 83604 & 89404 & 90519 & 0.91621 & 0.92710 & & 94850 & 95902 & .96943 & 97972 & התדסק. \\
\hline-2.6 & 77339 & 83582 & .89390 & 90507 & 0.91611 & & & & 5897 & & & \\
\hline 2.5 & 77298 & 3554 & & & & & & & & & & \\
\hline-2.4 & 77246 & 518 & 0.89 & 72 & & 674 & & 825 & & & 7963 & 987 \\
\hline-2.3 & 77179 & 0.83471 & 0.89321 & 0.90446 & 0.91 & 0.92654 & 0.93739 & .94811 & 95871 & 920 & 97957 & 98984 \\
\hline-2.2 & 77095 & 0.83413 & 0.89285 & 90414 & 0.91528 & 0.92630 & & .94794 & & & & \\
\hline-2.1 & 76989 & 83339 & 0.89239 & 373 & 0.9 & 599 & 692 & 772 & 841 & & & \\
\hline-2.0 & 156 & 248 & 0.89 & & & & & & & & & \\
\hline-1.9 & 0.76692 & 0.83134 & 0.89 & 260 & & & & 7712 & 793 & & 919 & 965 \\
\hline-1.8 & 0.76491 & 0.82995 & 0.89025 & 83 & & & & .94672 & 5761 & & & \\
\hline 1.7 & 0.76246 & 0.82826 & 0.88920 & 90089 & 0.91 & 0.9 & 0.9 & 622 & 722 & & & \\
\hline 1.6 & 5948 & & & & & & & & & & & \\
\hline-1.5 & .75589 & 0.82373 & 0.88 & 40 & & & & & & & & \\
\hline-1.4 & 0.75157 & 0.82076 & 0.88455 & 89676 & & & 0.93 & 4404 & & & & .98906 \\
\hline 1.3 & 74641 & 81722 & 0.88236 & 89482 & 0.90 & 924 & 120 & .94302 & 469 & & & \\
\hline .2 & 74026 & 301 & 77 & 52 & & & & & & & & \\
\hline 1.1 & 73295 & & 70 & & & & & 037 & & & & \\
\hline-1.0 & 72427 & 0.80214 & 0.87309 & 0.88660 & & & & & & & & \\
\hline 0.9 & .71398 & 79519 & 0.86884 & 283 & & & & 0.93672 & 971 & & & \\
\hline 0.8 & 70177 & 8699 & 0.86 & 342 & & & & & & & & \\
\hline 0.7 & 726 & 77733 & 0.85 & & & & & & & & & \\
\hline 0.6 & 0.66996 & 76592 & 0.85 & 0.86 & & & & & & & & \\
\hline-0.5 & 0.64924 & 0.75242 & 0.84 & 0.8 & & & & & & & & \\
\hline-0.4 & 0.62426 & 3640 & 0.83 & 0.85 & & & & & & & & \\
\hline-0.3 & 59385 & & & & & & & & & & & \\
\hline-0.2 & 55629 & 433 & 0.80 & & & & & & & & & \\
\hline-0.1 & 50894 & 0.66653 & 0.79 & & & & & & & & & \\
\hline 0.0 & 0.44721 & 0.63246 & 0.77 & 0.80 & & & & & & & & \\
\hline 0.1 & 36161 & 997 & & & & & & & & & & \\
\hline 0.2 & 22202 & & & & & & & & & & & \\
\hline 0.3 & - & & & & & & & & & & & \\
\hline 0.4 & - & 5968 & 0.64 & & & & & & & & & 05 \\
\hline 0.5 & - & 16635 & 0.59 & & & & & & & & & \\
\hline 0.6 & f: & - & 0.52 & & & & & & & & & \\
\hline 0.7 & - & - & & & & & & & & & & \\
\hline 0.8 & - & - & 0.23656 & & & & & & & & & 163 \\
\hline 0.9 & - & - & - & 0.14852 & 0.36155 & 26 & & & 190 & & 469 & \\
\hline 1.0 & - & - & - & - & & 0.34290 & & & & & & \\
\hline 1.1 & - & - & - & - & - & 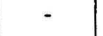 & & & & & & \\
\hline 1.2 & - & - & - & - & - & - & - & 0.36189 & & & & 895 \\
\hline 1.3 & - & - & - & - & - & 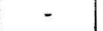 & - & - & 660 & & 602 & \\
\hline 1.4 & - & & - & & & & & - & 0.09680 & & & \\
\hline 1.5 & - & - & - & - & - & - & - & - & - & 0.31921 & & \\
\hline 1.6 & - & - & - & - & - & - & - & - & - & - & 1968 & 0.79689 \\
\hline 1.7 & - & - & - & - & - & - & - & - & - & - & 0.32007 & 0.74244 \\
\hline 1.8 & - & - & 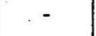 & & & 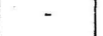 & & & - & - & - & \\
\hline & - & & & & & & & & & 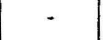 & 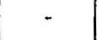 & 0.55094 \\
\hline 2.0 & - & - & - & - & - & - & - & - & - & - & - & 0.34768 \\
\hline 2.1 & - & - & - & - & - & & - & - & - & - & - & - \\
\hline
\end{tabular}


Table 4. Tabulated values of $C(z, P)$ for various values of $z$ and $P$

\begin{tabular}{|c|c|c|c|c|c|c|c|c|c|c|c|c|}
\hline$z \backslash P$ & 0.80 & 0.85 & 0.90 & 0.91 & 0.92 & 0.93 & 0.94 & 0.95 & 0.96 & 0.97 & 0.98 & 0.99 \\
\hline-3.0 & 0.10547 & 0.06744 & 0.03984 & 0.03511 & 0.03059 & 0.02625 & 0.02209 & 0.01808 & 0.01421 & 0.01048 & 0.00688 & 0.00338 \\
\hline-2.9 & 0.10913 & 0.06977 & 0.04122 & 0.03632 & 0.03164 & 0.02716 & 0.02285 & 0.01870 & 0.01470 & 0.01084 & 0.00711 & 0.00350 \\
\hline-2.8 & 0.11305 & 0.07227 & 0.04269 & 0.03762 & 0.03277 & 0.02813 & 0.02366 & 0.01937 & 0.01523 & 0.01123 & 0.00737 & 0.00363 \\
\hline-2.7 & 0.11728 & 0.07495 & 0.04427 & 0.03902 & 0.03399 & 0.02917 & 0.02454 & 0.02008 & 0.01579 & 0.01164 & 0.00764 & 0.00376 \\
\hline-2.6 & 0.12184 & 0.07785 & 0.04598 & 0.04051 & 0.03529 & 0.03029 & 0.02548 & 0.02085 & 0.01639 & 0.01209 & 0.00793 & 0.00390 \\
\hline-2.5 & 0.12679 & 0.08098 & 0.04781 & 0.04213 & 0.03670 & 0.03149 & 0.02649 & 0.02168 & 0.01705 & 0.01257 & 0.00825 & 0.00406 \\
\hline-2.4 & 0.13216 & 0.08437 & 0.04980 & 0.04389 & 0.03823 & 0.03280 & 0.02759 & 0.02258 & 0.01775 & 0.01309 & 0.00859 & 0.00423 \\
\hline-2.3 & 0.13802 & 0.08806 & 0.05196 & 0.04579 & 0.03988 & 0.03422 & 0.02879 & 0.02356 & 0.01852 & 0.01366 & 0.00896 & 0.00441 \\
\hline-2.2 & 0.14444 & 0.09209 & 0.05432 & 0.04786 & 0.04168 & 0.03576 & 0.03008 & 0.02462 & 0.01935 & 0.01427 & 0.00936 & 0.00461 \\
\hline-2.1 & 0.15151 & 0.09650 & 0.05689 & 0.05012 & 0.04365 & 0.03745 & 0.03150 & 0.02577 & 0.02026 & 0.01494 & 0.00980 & 0.00482 \\
\hline-2.0 & 0.15931 & 0.10135 & 0.05971 & 0.05260 & 0.04580 & 0.03929 & 0.03305 & 0.02704 & 0.02125 & 0.01567 & 0.01028 & 0.00506 \\
\hline-1.9 & 0.16797 & 0.10670 & 0.06281 & 0.05532 & 0.04817 & 0.04132 & 0.03475 & 0.02843 & 0.02234 & 0.01647 & 0.01080 & 0.00531 \\
\hline-1.8 & 0.17764 & 0.11263 & 0.06623 & 0.05833 & 0.05078 & 0.04355 & 0.03662 & 0.02996 & 0.02354 & 0.01736 & 0.01138 & 0.00560 \\
\hline-1.7 & 0.18848 & 0.11924 & 0.07003 & 0.06166 & 0.05367 & 0.04602 & 0.03869 & 0.03165 & 0.02487 & 0.01833 & 0.01202 & 0.00591 \\
\hline-1.6 & 0.20072 & 0.12662 & 0.07425 & 0.06536 & 0.05688 & 0.04877 & 0.04099 & 0.03352 & 0.02634 & 0.01941 & 0.01272 & 0.00626 \\
\hline-1.5 & 0.21460 & 0.13492 & 0.07897 & 0.06950 & 0.06046 & 0.05183 & 0.04 & 0.03561 & 0.02797 & 0.02061 & 0.01351 & 0.00664 \\
\hline-1.4 & 0.23047 & 0.14428 & 0.08426 & 0.07413 & 0.06447 & 0.05525 & 0.04642 & 0.03795 & 0.02980 & 0.02195 & 0.01439 & 0.00707 \\
\hline-1.3 & 0.24873 & 0.15492 & 0.09022 & 0.07934 & 0.06898 & 0.05910 & 0.04963 & 0.04056 & 0.03185 & 0.02346 & 0.01537 & 0.00755 \\
\hline-1.2 & 0.26991 & 0.16706 & 0.09697 & 0.08524 & 0.07408 & 0.06343 & 0.05326 & 0.04351 & 0.03415 & 0.02514 & 0.01647 & 0.00809 \\
\hline-1.1 & 0.29472 & 0.18100 & 0.10465 & 0.09193 & 0.07986 & 0.06835 & 0.05736 & 0.04684 & 0.03675 & 0.02705 & 0.01771 & 0.00870 \\
\hline-1.0 & 0.32406 & 0.19712 & 0.11343 & 0.09958 & 0.08644 & 0.07395 & 0.06 & 0.05063 & 0.03970 & 0.02921 & 0.01912 & 0.00939 \\
\hline-0.9 & 0.35919 & 0.21589 & 0.12352 & 0.10835 & 0.09399 & 0.08034 & 0.06 & 0.05494 & 0.04307 & 0.03167 & 0.02072 & 0.01017 \\
\hline-0.8 & 0.40188 & 0.23793 & 0.13518 & 0.11846 & 0.10267 & 0.08770 & 0.07346 & 0.05989 & 0.04691 & 0.03 & 0.02255 & 0.01106 \\
\hline-0.7 & 0.45470 & 0.26405 & 0.14875 & 0.13020 & 0.11273 & 0.09620 & 0.08051 & 0.06559 & 0.05134 & 0.03771 & 0.02464 & 0.01209 \\
\hline-0.6 & 0.52159 & 0.29532 & 0.16463 & 0.14391 & 0.12444 & 0.10607 & 0.08869 & 0.07218 & 0.05645 & 0.04143 & 0.02705 & 0.01326 \\
\hline-0.5 & 0.60897 & 0.33323 & 0.18337 & 0.16002 & 0.13816 & 0.11761 & 0.09822 & 0.07984 & 0.06239 & 0.0 & 0.02985 & 0.01462 \\
\hline-0.4 & 0.72836 & 0.37988 & 0.20566 & 0.17910 & 0.15435 & 0.13118 & 0.1 & 0.08881 & 0.06931 & 0.05 & 309 & 0.01619 \\
\hline-0.3 & 0.90317 & 0.43838 & 0.23242 & 0.20188 & 0.17361 & 0.147 & 0.12 & 0.0 & 0.07 & 0.0 & 0.03689 & 0.01803 \\
\hline-0.2 & 1.19255 & 0.51350 & 0.26487 & 0.22936 & 0.19670 & 0.16645 & 0.13827 & 0.11188 & 0.08704 & 0.06358 & 0.04134 & 0.02018 \\
\hline-0.1 & 1.82560 & 0.61321 & 0.30475 & 0.26285 & 0.22466 & 0.18955 & 0.15706 & 0.12679 & 0.09845 & 0.07179 & 0.04660 & 0.02272 \\
\hline 0.0 & 26825.9 & 0.75199 & 0.35449 & 0.30419 & 0.25888 & 0.21764 & 0.17976 & 0.14472 & 0.11210 & 0.08156 & 0.05284 & 0.02572 \\
\hline 0.1 & - & 0.96041 & 0.41770 & 0.356 & 0.30 & 0.25215 & 0.2 & 0.16 & 0.12 & 0.0 & 031 & 0.02929 \\
\hline 0.2 & - & 1.32065 & 0.50003 & 0.42233 & 0.35483 & 0.29514 & 0.2 & 0.19304 & 0.14855 & 0.10747 & 0.06928 & 0.03356 \\
\hline 0.3 & - & 2.20821 & 0.61089 & 0.50925 & 0.42358 & 0.34954 & 0.28429 & 0.22593 & 0.17307 & 0.12473 & 0.08014 & 0.03871 \\
\hline 0.4 & - & - & 0.76763 & 0.62731 & 0.51429 & 0.41976 & 0.33848 & 0.26712 & 0.20346 & 0.14593 & 0.09338 & 0.04495 \\
\hline 0.5 & - & - & 1.00756 & 0.79618 & 0.63837 & 0.51282 & 0.40863 & 0.31952 & 0.24159 & 0.17 & 965 & 0.05256 \\
\hline 0.6 & & - & 1.43476 & 1.05940 & 0.81750 & 0.64073 & 0.50183 & 0.38744 & 0.29009 & 0.20521 & 983 & 0.06191 \\
\hline 0.7 & $=$ & - & 2.58283 & 1.54563 & 1.10074 & 0.82647 & 0.63018 & 0.47767 & 0.35289 & 0.24710 & 0.15508 & 0.07348 \\
\hline 0.8 & - & - & - & 3.04736 & 1.63954 & 1.12241 & 0.81664 & 0.60164 & 0.43604 & 0.30115 & 0.18705 & 0.08790 \\
\hline 0.9 & - & - & - & - & 3.53702 & 1.69356 & 1.11316 & 0.78067 & 0.54949 & 0.37222 & 0.22803 & 0.10606 \\
\hline 1.0 & - & - & - & - & - & 3.85162 & 1.68050 & 1.06138 & 0.71116 & 0.46806 & 137 & 0.12913 \\
\hline 1.1 & - & - & - & - & - & - & 3.71239 & 1.57921 & 0.95791 & 0.60182 & 0.35212 & 0.15876 \\
\hline 1.2 & - & - & - & - & - & - & - & 3.13220 & 1.38562 & 0.79840 & 0.44829 & 0.19730 \\
\hline 1.3 & - & - & - & - & - & - & - & - & 2.40407 & 1.11354 & 0.58351 & 0.24816 \\
\hline 1.4 & - & - & - & - & - & - & - & - & - & 1.71709 & 0.78345 & 0.31653 \\
\hline 1.5 & - & - & - & - & - & - & - & - & - & 3.81776 & 1.10522 & 0.41059 \\
\hline 1.6 & - & - & - & - & - & - & - & - & - & - & 1.72081 & 0.54422 \\
\hline 1.7 & - & - & - & - & - & - & - & - & - & - & 3.80881 & 0.74328 \\
\hline 1.8 & - & - & - & - & - & - & - & - & - & - & - & 1.06408 \\
\hline 1.9 & - & : & - & - & - & - & - & - & - & - & - & 1.66967 \\
\hline 2.0 & - & - & - & - & - & - & - & - & - & - & - & 3.53687 \\
\hline 2.1 & - & - & - & - & - & - & - & - & $=$ & - & - & - \\
\hline
\end{tabular}

Maximum values of $\mathrm{z}$ for which $\mathbf{C}(\mathrm{z}, \mathrm{P})=\infty$ 
ble 5. Tabulated values of $D(z, P)$ for various values of $z$ and $P$.

\begin{tabular}{|l|l|l|l|l|l|l|l|l|l|l|l|l|}
\hline $\mathbf{P}$ & $\mathbf{0 . 8 0}$ & $\mathbf{0 . 8 5}$ & $\mathbf{0 . 9 0}$ & $\mathbf{0 . 9 1}$ & $\mathbf{0 . 9 2}$ & $\mathbf{0 . 9 3}$ & $\mathbf{0 . 9 4}$ & $\mathbf{0 . 9 5}$ & $\mathbf{0 . 9 6}$ & $\mathbf{0 . 9 7}$ & $\mathbf{0 . 9 8}$ & $\mathbf{0 . 9 9}$ \\
\hline
\end{tabular}

\begin{tabular}{|l|l|l|l|l|l|l|l|l|l|l|l|l|}
\hline .0 & 0.79003 & 0.87217 & 0.92944 & 0.93875 & 0.94745 & 0.95561 & 0.96324 & 0.97040 & 0.97711 & 0.98340 & 0.98929 & 0.99482 \\
\hline
\end{tabular}

$\begin{array}{llll}7.9 & 0.78983 & 0.8\end{array}$

\begin{tabular}{ll|l}
8 & 0.78956 \\
\hline
\end{tabular}

.70 .78919

1.60 .788720 .87138

\begin{tabular}{l|l|l|l|l|l}
.5 & 0.78810 & 0.87101 \\
\hline
\end{tabular}

\begin{tabular}{l|l|l|l|l}
1.4 & 0.78730 & 0.87052 \\
\hline
\end{tabular}

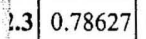

$\begin{array}{llll}\text { L.2 } & 0.78498 & 0.86913\end{array}$

2.10 .78335

2.00 .78131

1.90 .77879

\begin{tabular}{l|l|l|l|}
1.8 & 0.77570 \\
\hline
\end{tabular}

1.70 .77191

1.60 .76731

1.50 .76175

1.40 .75504

1.30 .74700

1.20 .73738

\begin{tabular}{l|l|l|}
1.1 & 0.72588
\end{tabular}

\begin{tabular}{l|l|l|l|l|l|l|l|l|}
1.0 & 0.71214 \\
\hline
\end{tabular}

\begin{tabular}{l|l|l|l|l|l|l|}
0.9 & 0.69571
\end{tabular}

\begin{tabular}{l|l|l|}
0.8 & 0.67602 \\
\hline
\end{tabular}

\begin{tabular}{ll|l|l|l|l|l|}
0.7 & 0.65230 \\
\hline
\end{tabular}

\begin{tabular}{lll}
0.6 & 0.62355 \\
\hline
\end{tabular}

$\begin{array}{ll}-0.5 & 0.58832\end{array}$

\begin{tabular}{l|l}
-0.4 & 0.54444 \\
\hline
\end{tabular}

\begin{tabular}{ll|l}
$-\mathbf{0 . 3}$ & 0.48839 \\
-0.2 & 0.413557
\end{tabular}

\begin{tabular}{ll|}
-0.2 & 0.41357 \\
\hline
\end{tabular}

\begin{tabular}{l|l}
-0.1 & 0.30368
\end{tabular}

0.00 .00002

0.1 .

0.2

0.3

0.4

0.5

0.

0.7

0.8

0.

1.0

1.2

1.3

1.4

1.5

1.

1.7

1.8

1.9

2.0

2.1

0.86694

0.86543

0.86358

0.85529

0.85133

0.84661
0.84098

0.83431

0.82641

0.77739

0.75893

0.73685

0.58824

0.29958

\section{\begin{tabular}{llllllll}
0.93869 & 0.94740 & 0.95556 & 0.96321 & 0.97037 \\
\hline
\end{tabular}}

0.938600 .94733

\begin{tabular}{l|l|l|l|l|l}
0.95550 & 0.96316 & 0.97033 \\
\hline
\end{tabular}

\begin{tabular}{l|l|l|l|}
0.92916 & 0.93850 & 0.94724 \\
\hline
\end{tabular}

0.92900

0.92879

0.93836

0.94712

0.946960 .95519

0.946760 .95502

\begin{tabular}{ll|l|l|l}
0.94650 & 0.95480 \\
\hline
\end{tabular}

0.94618

0.94577

0.92720

0.92569

0.93620

0.94526

0.95453

0.861320 .92341

0.858590 .92189

0.92007

0.91528

0.91219

0.9264

0.90854

0.92055

0.90423

0.91681

$\begin{array}{lll}0.81706 & 0.89917 \\ 0.80600\end{array}$

0.91242

\begin{tabular}{ll|l}
0.80600 & 0.89321 & 0
\end{tabular}

0.90725

0.88622

0.87800

0.90120

0.89409

0.85696

0.710270 .84351

0.88575

0.87593

0.86437

0.677980 .82756

0.85068

0.638190 .80853

0.83441

0.523590 .75799

$\begin{array}{lll}0.43541 & 0.72406\end{array}$

0.68183

0.62813

0.81497

0.79155

0.76307

0.72802

0.55753

0.68417

0.94463

0.94386

0.94292

0.94179

0.94042

0.93878

0.93684

0.93453

\begin{tabular}{ll|l}
0.93180 & 0.94233
\end{tabular}

0.928590 .93961

0.92481

0.920380 .93268

0.91519

0.90911

0.90198

0.89361

0.88376

0.87213

0.85836

0.84195

0.82229

0.79854

0.76955

0.73373

0.92830

0.92316

0.91715

0.45913 0.62801

0.68867

0.91011

0.90184

0.89209

0.88058

0.86691

0.85060

0.83099

0.80723

0.77815

0.74205

0.301090 .44784

0.63062

0.69646

0.44784

\begin{tabular}{ll|l}
0.55290 & 0.63741
\end{tabular}

0.44121

0.55787

0.24479

0.44253

0.23456

0.2

\begin{tabular}{l|l|l|l|l}
0.96309 & 0.97028 \\
0.96301 & 0.97021 & 0.9 \\
0.96290 & 0.97012 & 0.5
\end{tabular}

0.962900 .97012

0.962760 .97001

0.96257

0.96234

0.96986

0.96967

6

0.96170

0.96125

0.96071

0.96005

0.95924

0.95828

0.95713

0.95575

0.95413

0.94995

0.94730

0.94420

0.94057

0.93632

0.93136

0.92554

0.91872

0.91070

0.90125

0.89006

0.87676

0.86084

0.84166

0.81835

0.78972

0.83277

0.75408

0.80537

0.70891

0.77117

0.65022

0.72775

0.67129

0.59518

.25057

0.48569

0.29951

$\begin{array}{lll}0.97709 & 0.98338\end{array}$

0.989280 .99481

\begin{tabular}{|l|l|l|l|l|}
0.97706 & 0.98336 & 0.98927 & 0.99481 \\
\hline
\end{tabular}

\begin{tabular}{ll|l|l|l|l|l|l|}
0.97702 & 0.98333 & 0.98925 & 0.99480 \\
\hline
\end{tabular}

\begin{tabular}{ll|l|l|l|}
0.97696 & 0.98329 & 0.98922 & 0.99479 \\
\hline
\end{tabular}

\begin{tabular}{|l|l|l|l|l|}
0.97689 & 0.98324 & 0.98919 & 0.99477 \\
\hline
\end{tabular}

\begin{tabular}{ll|l|l|l}
0.97680 & 0.98317 & 0.98915 & 0.99475
\end{tabular}

0.97669

0.97654

0.98309

0.98299

$\begin{array}{lll}0.97636 & 0.98285\end{array}$

$\begin{array}{lll}0.97614 & 0.98269\end{array}$

0.975860 .98248

$\begin{array}{lll}0.97551 & 0.98223\end{array}$

$0.97510 \quad 0.98193$

0.97459

0.97398

0.97326

0.98156

0.98112

\begin{tabular}{l|l|l}
0.97240 & 0.97996 \\
\hline
\end{tabular}

0.97138

0.97922

$\begin{array}{lll}0.97017 & 0.97834\end{array}$

\begin{tabular}{ll|l}
0.96876 & 0.97731 \\
\hline
\end{tabular}

$0.96710 \quad 0.97610 \quad 0.984560 .99252$

\begin{tabular}{|l|l|l|l|l|}
0.96516 & 0.97469 & 0.98365 & 0.99207 \\
\hline
\end{tabular}

\begin{tabular}{ll|l|l|l|}
0.96289 & 0.97304 & 0.98258 & 0.99156 \\
\hline
\end{tabular}

\begin{tabular}{ll|l}
0.96024 & 0.97111
\end{tabular}

0.95715

0.96625

0.981340 .99095

0.949310 .96319

0.99025

0.94436

0.938540 .9554

$\begin{array}{lll}0.93169 & 0.95047\end{array}$

0.92360

0.91398

0.90249

0.88868

0.87196

0.85156

0.82638

0.79494

0.75502

0.70323

0.63389

0.53600

0.38068

0.93774

0.92953

0.91971

0.90788

0.89354

0.87600

0.85436

0.82733

0.79309

0.74892

0.69047

0.61005

0.49121

0.27642

$\begin{array}{lll}0.76821 & 0.89403\end{array}$

\begin{tabular}{ll|l}
0.71040 & 0.87030
\end{tabular}

\begin{tabular}{ll|l}
0.63007 & 0.83944
\end{tabular}

0.510270 .79858

0.29299

0.66496

0.54726

0.33635 